This item was submitted to Loughborough's Research Repository by the author.

Items in Figshare are protected by copyright, with all rights reserved, unless otherwise indicated.

\title{
Influence of nonideal voltage measurement on parameter estimation in permanent-magnet synchronous machines
}

PLEASE CITE THE PUBLISHED VERSION

http://dx.doi.org/10.1109/TIE.2011.2162214

PUBLISHER

(C) IEEE

VERSION

AM (Accepted Manuscript)

LICENCE

CC BY-NC-ND 4.0

\section{REPOSITORY RECORD}

Liu, Kan, Zi-Qiang Zhu, Qiao Zhang, and Jing Zhang. 2019. "Influence of Nonideal Voltage Measurement on Parameter Estimation in Permanent-magnet Synchronous Machines". figshare.

https://hdl.handle.net/2134/25040. 


\title{
Influence of Non-ideal Voltage Measurement on Parameter Estimation in Permanent Magnet Synchronous Machines
}

\author{
Kan Liu, Z.Q. Zhu, Fellow, IEEE, Qiao Zhang, Member, IEEE, and Jing Zhang
}

\begin{abstract}
This paper investigates the influence of non-ideal voltage measurements on the parameter estimation of permanent magnet synchronous machines. The influence of non-ideal voltage measurements, such as the DC bus voltage drop, zero shift in the amplifier and voltage source inverter nonlinearities, on the estimation of different machine parameters is investigated by theoretical and experimental analysis. For analysis, a model reference adaptive system based estimator is firstly described for the parameter estimation of the $q$-axis inductance, stator winding resistance and rotor flux linkage. The estimator is then applied to a prototype surface-mounted permanent magnet synchronous machine to investigate the influence of non-ideal voltage measurement on the estimation of various machine parameter values. It shows that at low speed the inverter nonlinearity compensation has significant influence on both the rotor flux linkage and winding resistance estimation, while at high speed its only significant influence is on the winding resistance estimation and negligible influence on the rotor flux linkage estimation. In addition, the inverter nonlinearity compensation will not influence the $q$-axis inductance estimation when it is under $i_{d}=0$ control. However, the DC bus voltage drop due to the load variation an d zero shift in the amplifier will significantly influence the $q$-axis inductance estimation.
\end{abstract}

Index Terms - inverters, stators, rotors, magnetic flux linkage, parameter estimation, permanent magnet machines, neural networks, system identification

\section{NOMENCLAT URE}

$R$

$L_{d}, L_{q}$

$\psi_{m}$

$T_{S}$

$i_{a s}, i_{b s}, i_{b s}$

$V_{a s}, V_{b s}, V_{b s}$

$V_{a n}, V_{b n}, V_{b n}$

$\wedge$

$V_{a n}^{*}, V_{b n}^{*}, V_{c n}^{*}$
Stator winding resistance $(\Omega)$.

$d q$-axis inductances $(\mathrm{H})$.

Rotor flux linkage (Wb).

Sampling period $(\mu \mathrm{s})$.

Stator abc phase currents (A).

Line-to-neutral stator abc phase voltages (V). abc phase-to-center voltages (V).

Denotes a variable specified by PI regulator. Denotes an estimated value.

Manuscript received December 14, 2010. Revised May 22, 2011. Accepted for publication June 27, 2011. Copyright (c) 2009 IEEE. Personal use of this material is permitted. However, permission to use this material for any other purposes must be obtained from the IEEE by sending a request to pubs-permissions@ieee.org.

K. Liu and Z.Q. Zhu are with the Department of Electronic and Electrical Engineering, University of Sheffield, UK (e-mail: 1kan@live.cn; Z.Q.Zhu@sheffield.ac.uk).

J. Zhang is with the School of Electrical and Information Engineering, Hunan University, China (e-mail: zhangi@hnu.cn).

Q. Zhang is with the Department of Control Science and Engineering, Huazhong University of Science and Technology, China (e-mail: zq_zjuee@hotmail.com).

$u_{d}{ }^{*}, u_{q}{ }^{*}$
$V_{a s}^{\prime}, V_{b s}^{\prime}, V_{c s}^{\prime}$
$\hat{R}$
$\hat{\psi}_{m}$
$\hat{L}$
$E$
$T_{c o m}$
$T_{o n}, T_{o f f}$
$T_{d}$
$V_{c o m}$
$\omega, \theta$
$V_{d c}, V_{m}$
$u_{d}, u_{q}$
$i_{d}, i_{q}$
$V_{s}^{*}$
$\Delta R$
$\Delta, \gamma$
$U$
$\psi_{m}$

$d q$-axis reference voltages measured from the PI regulators (V).

abc phase distorted voltages (V).

Estimated stator winding resistance $(\Omega)$.

Estimated rotor flux linkage $(\mathrm{Wb})$.

Estimated inductance value $(\mathrm{H})$.

abc phase distorted voltage due to inverter nonlinearity (V).

Compensation time $(\mu \mathrm{s})$.

Turn on/off time of IGBT $(\mu \mathrm{s})$.

Control dead time of the switch $(\mu \mathrm{s})$.

Constant of distorted voltage due to inverter nonlinearity in $d q$-axis reference frame (V). Electrical angular speed $(\mathrm{rad} / \mathrm{s})$ and rotor position (rad).

Actual and measured real-time DC bus voltage (V).

Actual $d q$-axis voltages (V).

Actual $d q$-axis currents (A).

Amplitude of line-to-neutral stator reference phase voltage (V).

Stator winding resistance estimation error due to VSI nonlinearity $(\Omega)$.

Rotor flux linkage estimation error due to VSI nonlinearity (Wb).

Distorted voltage due to the variation of DC bus voltage and zero shift in the amplifier (V).

Angles between voltage/current vector and $q$-axis (rad), respectively.

\section{INT RODUCTION}

P ermanent magnet synchronous machines (PMSM) are now widely used in many applications, ranging from indus trial servo drives, automotive power trains and wind power generation, to aerospace, due to their high power/torque density, high efficiency and excellent control performance. In order to realize a high performance and reliable PMSM drive system, accurate PMSM parameters are essential. Often on-line estimation of parameters is required so the controller parameters and system conditions can be updated, especially for sensorless control [1]-[5] and optimal PI controller design. Much literature has made contributions [4]-[19] to obtain parameters with different on-line estimation strategies from the measured machine electrical signals, such as the model reference adaptive system (MRAS) [4]-[7], recursive least square algorithms (RLS) [8]-[11], Neural 
Network (NN) technology [12], [15], [19], and extended Kalman filter (EKF) [13]. For example, some literature proposes the use of the MRAS estimator to identify values of PMSM parameters, then utilized to improve the performance of sensorless control [4], [5]. Similarly, other literature proposes the use of the RLS estimator to identify values of PMSM parameters for improving the performance of sensorless control [8], [9]. In fact, existing methods for identifying the values of PMSM parameters [4]-[19], irrespective of the algorithm, such as MRAS, EKF, RLS and $\mathrm{NN}$, etc., are employed in these methods, the majority based on solving the PMSM equations by using measured stator currents and voltages.

However, in a PMSM vector control system, the utilized voltages in the PMSM parameter estimators cannot be directly measured from the stator winding terminals and are usually measured from the output voltage of the PI regulator and specified DC bus voltage. Thus, since non-ideal voltage measurements usually exist, such as the DC bus voltage drop, zero shift in the amplifier and voltage source inverter nonlinearities, the foregoing estimation strategies [4]-[19] should cooperate with an appropriate voltage measurement scheme to achieve high accuracy of estimation results. Otherwise, the accuracy of estimated parameters may suffer from the non-ideal voltage measurement. Therefore, some papers in literature have investigated the influence of VSI nonlinearities on unbalanced/nonlinear loads [20] and sensorless control [21]. Furthermore, some papers have investigated the influence of inaccurate machine parameters on the performance of sensorless control [22], [23]. However, there is still no literature systematically investigating the influence of non-ideal voltage measurement due to VSI nonlinearity, DC bus voltage drop and zero shift in the amplifier on the estimation of different PMSM parameters. For instance, Morimoto et al. [24] proposed the estimation of distorted voltage due to VSI nonlinearity at PMSM standstill and used the estimated distorted voltage to compensate the estimated PMSM parameters when starting the PMSM. However, the method in [24] neither investigated the influence of VSI nonlinearity on the estimation of different mach ine parameters, nor took into account the influence of the DC bus voltage drop and zero shift in the amp lifier.

In this paper, the influence of non-ideal voltage measurement on the estimation of various PMSM parameter values is systematically investigated by theory and experimental analysis. Revealing that at low speed the VSI nonlinearity compensation has significant influence on both the rotor flux linkage and stator winding resistance estimation, while at high speed it has only significant influence on the winding resistance estimation, but negligible influence on the rotor flux linkage estimation. In addition, the VSI nonlinearity compensation will not influence the $q$-axis inductance estimation when it is under $i_{d}=0$ control. However, the DC bus voltage drop due to load variation and zero shift in the amplifier will influence the $q$-axis inductance estimation significantly. For analysis, a MRAS based estimator is described to estimate the $q$-axis inductance, stator winding resistance and rotor flux linkage of a non-salient pole SPMSM prior to the proposed investigation. Since the utilized MRAS estimator is based on the steady-state PMSM equations, which are the same as most other estimators using
EKF, RLS and NN, etc., the analysis and conclusion based on the used MRAS estimator can also be applied to other estimators based on solving the steady-state PMSM equations by using the measured stator currents and voltages. Moreover, existing methods for inverter nonlinearity compensation can be categorized as, inverter model based compensation, system identification algorithm based on-line compensation and voltage harmonic analysis based compensation. However, since the system identification algorithm based on-line compensation [28]-[32] needs assistance from accurate mach ine parameters and the voltage harmonic analysis based compensation [33]-[35] needs high frequency AD converter sampling and usually suffers from the system noises, the inverter model based compensation [25]-[27] is preferable for compensating the inverter nonlinearity in PMSM parameter estimation. Thus, the inverter model based compensation proposed in [26] and [27] for considering all the inverter nonlinearities will be emp loyed for this investigation.

\section{MACHINE MODEL}

Assuming that the employed SPMSM has negligible cross-coupling magnetic saturation, structural asymmetry, iron losses, magnet eddy current loss, and harmonics in the descriptive functions of windings, rotor anisotropy and coercive force of magnets, the $d q$-axis equations of the SPMSM are given by:

$$
\begin{aligned}
& \frac{d i_{d}}{d t}=-\frac{R}{L_{d}} i_{d}+\frac{L_{q}}{L_{d}} \omega i_{q}+\frac{u_{d}}{L_{d}} \\
& \frac{d i_{q}}{d t}=-\frac{R}{L_{q}} i_{q}-\frac{L_{d}}{L_{q}} \omega i_{d}+\frac{u_{q}}{L_{q}}-\frac{\psi_{m}}{L_{q}} \omega
\end{aligned}
$$

Since there is minor variation in the $d q$-axis inductances for the SPMSM, they will be regarded as constant $\left(L_{d}=L_{q}=L\right)$ throughout this paper.

The steady-state discrete equations of $(1)$ are:

$$
\begin{aligned}
& u_{d}(k)=R i_{d}(k)-L \omega(k) i_{q}(k) \\
& u_{q}(k)=R i_{q}(k)+L \omega(k) i_{d}(k)+\psi_{m} \omega(k)
\end{aligned}
$$

where ' $k$ ' is the index of the discrete sampling instant. Clearly, as can be seen from (2), if the $d q$-axis voltages obtained from the PI regulator mis match the actual voltages, the steady-state estimation results based on the $d q$-axis equation will be inaccurate.

\section{EST IMAT OR DESIGN AND INVERTER COMPENSATION}

A MRAS based PMSM parameter estimator is described in this section and the modeling of VSI nonlinearity proposed in [26] will be used for the analysis in section IV.

\section{A. MRAS Based Estimator Design}

Take (1) as the reference model, it can be transformed into: $\dot{X}=\mathrm{AX}+\mathrm{Br}+\mathrm{Cl}$

where $A=\left[\begin{array}{cc}-\alpha & \omega \\ \omega & -\alpha\end{array}\right], \alpha=\frac{R}{L}, B=\frac{1}{L}, C=-\frac{\psi_{m}}{L}, X=\left[\begin{array}{c}i_{d} \\ i_{q}\end{array}\right]$, $r=\left[\begin{array}{l}u_{d} \\ u_{q}\end{array}\right], l=\left[\begin{array}{l}0 \\ \omega\end{array}\right]$.

Similarly, the variable model can be shown as follows:

$\dot{\hat{X}}=\hat{A} \hat{X}+\hat{B} r+\hat{C} l$ 
where $\hat{A}=\left[\begin{array}{cc}-\hat{\alpha} & \omega \\ \omega & -\hat{\alpha}\end{array}\right], \hat{\alpha}=\frac{\hat{R}}{\hat{L}}, \hat{B}=\frac{1}{\hat{L}}, \hat{C}=-\frac{\hat{\psi}_{m}}{\hat{L}}$, $\hat{X}=\left[\begin{array}{c}\hat{i}_{d} \\ \hat{i}_{q}\end{array}\right], r=\left[\begin{array}{l}u_{d} \\ u_{q}\end{array}\right], l=\left[\begin{array}{c}0 \\ \omega\end{array}\right]$

$u_{d}$ and $u_{q}$ are the inputs of the SPMSM and the variable model whose outputs are currents. The parameters and variables with ' $\wedge$ ' are obtained fro $m$ the variable model.

By using Lyapunov second theorem on stability, the stator inductance, winding resistance and rotor flux linkage estimators are shown as follows and the design processes are shown in Appendix A:

$\frac{1}{\hat{L}}=\frac{1}{L_{0}}+\int_{0}^{t}\left[u_{d}\left(i_{d}-\hat{i}_{d}\right)+u_{q}\left(i_{q}-\hat{i}_{q}\right)\right] d t$

$\hat{R}=R_{0}-\hat{L} \int_{0}^{t}\left[\hat{i}_{d}\left(i_{d}-\hat{i}_{d}\right)+\hat{i}_{q}\left(i_{q}-\hat{i_{q}}\right)\right] d t$

$\hat{\psi}_{m}=\psi_{m 0}-\hat{L} \int_{0}^{t} \omega\left(i_{q}-\hat{i}_{q}\right) d t$

where $L_{0}, R_{0}$ and $\psi_{m 0}$ are the initial values of estimated inductance, winding resistance and rotor flux linkage.

\section{B. Compensation of Inverter Nonlinearity Voltage}

Cited from [26], Fig. 1 shows the three phase PWM inverter with a PMSM load and Fig. 2 shows the ideal and actual IGBT drive signals for phase A. The reference voltage is the area between $t_{1}$ and $t_{2}$ while the actual voltage, considering the control dead-time and conducting time delay of the switch, is the area between $t_{3}$ and $t_{4}\left(i_{a s}>0\right)$ or $t_{5}$ and $t_{6}$ $\left(i_{a s}<0\right)$. From Fig. 2(c), the voltage error depends on the direction of the phase current and the length of $T_{d}, T_{o n}$ and $T_{\text {off }}$.

Thus, it is proposed in [26] that the actual phase A output voltage can be obtained by:

$V_{a n}=V_{a n}^{*}+\operatorname{sign}\left(i_{a s}\right) E$

where $\operatorname{sign}(i)=\left\{\begin{array}{l}1, i>=0 \\ -1, i<0\end{array}\right.$

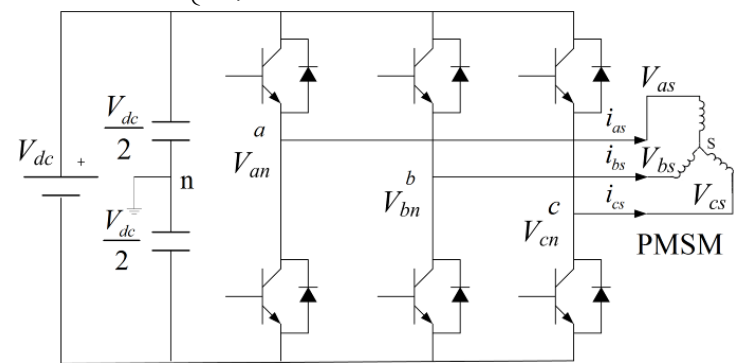

Fig. 1. Three-phase PWM inverter with aPMSM load.

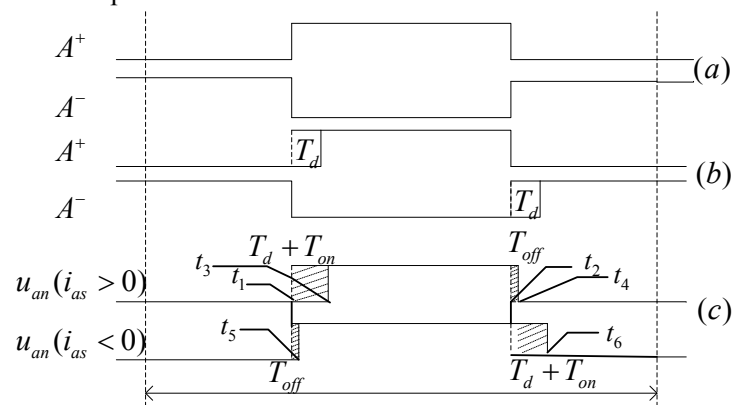

Fig. 2. Inverter output voltage and IGBT drive signal. (a) Ideal IGBT drive signal. (b) Actual drive signal with dead-time. (c) Actual output voltage with dead-time and switch on/off time.
$E$ represents the error due to non-ideal switching and the method proposed in [26] will be applied to obtain the value of $E$. As detailed in [26], for phase A winding voltage generation, the relationship between the commanded and actual time duration of PWM wave can be:

$$
T_{a}=T_{a}^{*}+\operatorname{sign}\left(i_{a s}\right) M
$$

where $T_{a}^{*}$ is the commanded time and $T_{a}$ is the actual time. $M$ is the total time error.

$M=T_{\text {com }}+T_{\text {off }}-T_{\text {on }}-T_{d}$

In [26], it is suggested that the length of $T_{c o m}$ may be adjusted to eliminate the distorted voltage $(E)$ and the actual phase A voltage by:

$$
V_{a s}=V_{a s}^{*}+V_{a s}^{\prime}-\frac{1}{2}\left(r_{c e}+r_{d}\right) i_{a s}
$$

where $r_{c e}$ and $r_{d}$ are the on-state slope resistances of the active switch and freewheeling diode, respectively. In real applications, $\frac{1}{2}\left(r_{c e}+r_{d}\right) i_{a s}$ acts as a part of the stator winding resistance. $V_{a s}^{\prime}$ is the distorted voltage and can be shown as follows:

$V_{a s}^{\prime}=\frac{1}{6}\left(V_{d c} \frac{M}{T_{s}}-V_{c e 0}-V_{d 0}\right)\left(2 \operatorname{sign}\left(i_{a s}\right)-\operatorname{sign}\left(i_{b s}\right)-\operatorname{sign}\left(i_{c s}\right)\right)$

where $V_{d c}=36 \mathrm{~V}$ in this paper. $V_{c e 0}$ and $V_{d 0}$ are the threshold voltages of the active switch and freewheeling diode, respectively. When $V_{a s}{ }^{\prime}=0, T_{\text {com }}$ can be obtained as follows:

$T_{\text {com }}=t_{d}-T_{o f f}+T_{o n}+T_{s} \frac{V_{c e 0}+V_{d 0}}{V_{d c}}$

Therefore, $E$ can be obtained as:

$E=\frac{-T_{c o m}}{2 T_{s}} V_{d c}$

Similarly, the voltages for the other two phases can be compensated in the same way.

\section{EXPERIMENTAL INVESTIGATION}

In this section, the hardware platform for the PMSM drive system is firstly introduced. Then, the MRAS based estimator is implemented in the PMSM drive system and the influence of non-ideal voltage measurement on different PMSM parameters is investigated through theoretical and experimental analys is.

\section{A. Machine Drive System}

The described MRAS based parameter estimation method is applied on a DSP (TMS320LF2812) based vector control PMSM drive system. All the experimental results are on-line commissioning results, which are recorded in external RAM of the DSP control board. The sampling period $T_{s}$ is set to $83.3 \mu s$. The employed VSI is a Mitsubishi PS21867 whose typical electrical characters (from the Mitsubishi official datasheet) are shown in Table I. Fig. 3 shows the prototype motor drive system and the SPMSM design parameters shown in Table II are the actual measured machine parameters. The 12-slot/10-pole PMSM used is a fractional slot motor, equipped with surface-mounted NdFeB magnets, previously developed for servo applications and has a rated torque of $5.5 \mathrm{Nm}$ at $400 \mathrm{r} / \mathrm{min}$. A control diagram of the whole 
system is shown in Fig. 4. In the following experiments the DC link is connected with a commercial DC power source whose output is fixed to $36 \mathrm{~V}$. The rotating electrical angular speed and load are constant via the current loop PI controller. In addition, the waveforms of the PMSM three-phase currents are shown in Fig. 5.

\section{B. Influence from Voltage Measurement Non-idealities}

As detailed in [12], under $i_{d}=0$ control, it is impossible to solve for stator winding resistance and rotor flux linkage simultaneously due to rank deficient problems, while the $q$-axis inductance can be individually estimated from the $d$-axis equation. Therefore, in the following investigation, the $q$-axis inductance will be individually estimated at $i_{d}=0$ control. Then, similar to the schemes proposed in [13]-[15], a flux weakening current $\left(i_{d}=-2 \mathrm{~A}\right)$ is transiently injected to activate the winding resistance term in the $d$-axis equation, and the $d q$-axis inductances are regarded to be $L_{d}=L_{q}$ so that the stator winding resistance and rotor flux linkage can be simultaneously solved from the steady-state $d q$-axis equations. Although this assumption that $L_{d}=L_{q}$ will cause an error in the estimation of rotor flux linkage and stator winding resistance, due to variation in $d q$-axis inductance, it will not inconvenience the analys is of the parameter estimation error caused by voltage measurement non-idealities because we only need to analy ze the variation of es timated results, with or without taking into account the non-ideal voltage measurement.

In the following investigations, the DC bus voltage will be measured in real-time using a DC voltage sensor to avoid the influence due to the on-load voltage drop. The schematic diagram of the proposed investigation is shown in Fig. 6. Under ideal conditions, the real-time DC bus voltage $V_{m}$ will be equal to the actual DC bus voltage $V_{c d}$ and is measured using a DC voltage sensor. However, it is known that there may be a zero shift in the amplifier, which will introduce a non-zero DC offset $V_{\text {offset }}$ in DC voltage sensor and make $V_{m} \neq V_{d c}$. Therefore, as detailed in Fig. 6, this DC offset $V_{\text {offse }}$ will be measured with the PMSM at standstill and will be utilized to co mpensate the measured real-time DC bus voltage $V_{m}$ when the PMSM is started. Finally, the actual DC bus voltage $V_{d c}$ can be obtained by $V_{m}-V_{o f f s e t}$. In addition, the method detailed in section III B will be utilized for the compensation of VSI nonlinearity.

At $\omega=157 \mathrm{rad} / \mathrm{s}$, Fig. 7(a) shows the es timated $L_{q}$ under $i_{d}=0$ control without taking into account all the non-ideal voltage measurements. For co mparis on, Fig. 7(b) shows the estimated $L_{q}$ under $i_{d}=0$ control, which takes into account the VSI nonlinearity compensation, measurement of the DC bus voltage variation and the DC offset due to zero shift. Comparing Fig. 7(a) with Fig. 7(b), it is evident that the estimated result in Fig. 7(b) is much closer to the nominal value of the $q$-axis inductance shown in Table II due to its consideration of non-ideal voltage measurement. Further, from Fig. 7(b), it shows that the influence from VSI nonlinearity compensation on the $q$-axis inductance estimation is negligible, which can be explained as follows:

As detailed in literature [30], the steady-state $d q$-axis equations can be shown as follows:

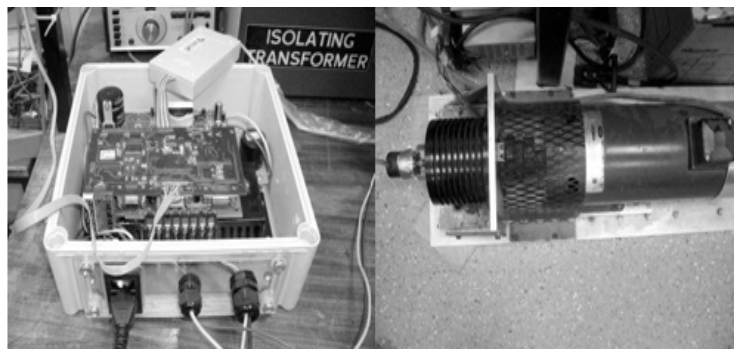

Fig. 3. Prototype DSP based PMSM drive system.

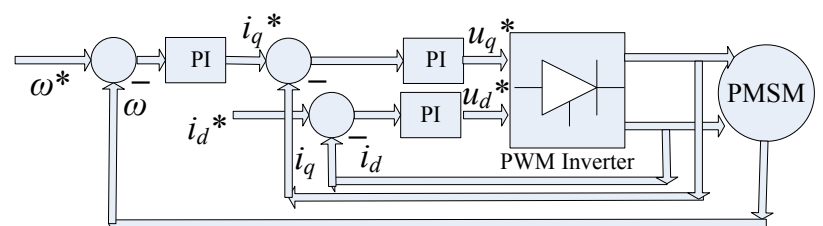

Fig. 4. System control diagram.

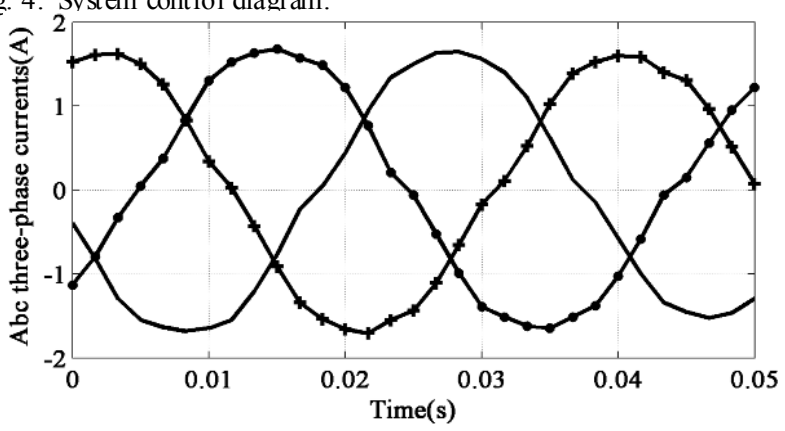

Fig. 5. Three-phase current waveforms.

TABLE I

TYPICAL ELECTRICAL P ARAMETERSOF VSI (FROM MIT SUBISHI P S2 1867 DATASHEET)

\begin{tabular}{ll}
\hline Turn off delay $T_{o f f}$ & $1.7 \mu \mathrm{s}$ \\
Turn on delay $T_{o n}$ & $1.3 \mu \mathrm{s}$ \\
Switch control dead time $t_{d}$ & $2 \mu \mathrm{s}$ \\
Voltage drop of the active $\operatorname{switch}\left(25^{\circ} \mathrm{C}\right) V_{c e 0}$ & $1.5 \mathrm{~V}$ \\
Voltage drop of the freewheeling diode $\left(25^{\circ} \mathrm{C}\right) V_{d 0}$ & $1.6 \mathrm{~V}$ \\
Supply voltage Vcc range & $0 \sim 400 \mathrm{~V}$ \\
\hline
\end{tabular}

TABLE II

DESIGN P ARAMETERS AND SPECIFICATION OF PMSM

\begin{tabular}{ll}
\hline Rated current & $4 \mathrm{~A}$ \\
Rated speed & $400 \mathrm{rpm}$ \\
DC link voltage & $36 \mathrm{~V}$ \\
Nominal phase resistance $\left(T=25^{\circ} \mathrm{C}\right)$ & $0.33 \Omega$ \\
Nominal terminal wire resistance & $0.043 \Omega$ \\
Nominal self inductance & $2.91 \mathrm{mH}$ \\
Nominal mutual inductance & $-0.330 \mathrm{mH}$ \\
Nominal d-axis inductance & $3.24 \mathrm{mH}$ \\
Nominal q-axis inductance & $3.24 \mathrm{mH}$ \\
Nominal amplitude of flux induced by magnets & $0.0776 \mathrm{~Wb}$ \\
Inertia & $0.8 \mathrm{e}-5 \mathrm{kgm}^{2}$ \\
Number of pole pairs & 5
\end{tabular}

Note: Nominal values are measured.

$$
\begin{aligned}
{\left[\begin{array}{c}
u_{d}^{*}(k)+D d(k) V_{c o m} \\
u_{q}^{*}(k)+D q(k) V_{c o m}
\end{array}\right] } & =\left[\begin{array}{c}
-L_{q} i_{q}(k) \\
L_{d} i_{d}(k)+\psi_{m}
\end{array}\right] \omega(k)+R\left[\begin{array}{c}
i_{d}(k) \\
i_{q}(k)
\end{array}\right] \\
& +U\left[\begin{array}{c}
\cos (\phi) \\
-\sin (\phi)
\end{array}\right]
\end{aligned}
$$

$V_{c o m}=\frac{1}{6}\left(\frac{T_{o f f}-T_{o n}-T_{d}}{T_{s}} V_{d c}-V_{c e 0}-V_{d 0}\right)$

As detailed in [28]-[32], the value of $V_{\text {com }}$ can be regarded as a constant when the PMSM is in steady state, and it varies as the working condition of PMSM changes. In addition, as detailed in [30], $U$ is the function of actual DC bus voltage $V_{d c}$ and measured real-time DC bus voltage $V_{m}$, which is expressed as follows: 


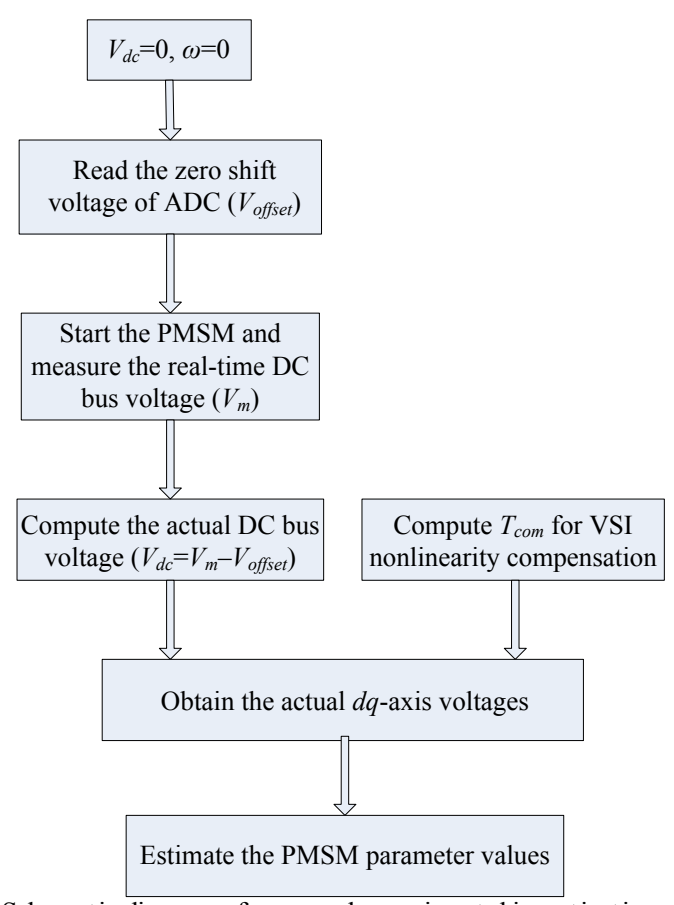

Fig. 6. Schematic diagram of proposed experimental investigation.

$$
U=\frac{V_{s}^{*}\left(V_{m}-V_{d c}+V_{c e 0}-V_{d 0}\right)}{V_{m}}
$$

In reality, since there exists a zero shift in the amplifier and DC bus voltage drop when on load, $V_{m}$ will differ slightly from $V_{d c}$. In addition, $D d$ and $D q$ are functions of rotor position $\theta$ and the directions of the three phase currents, which can be expressed as follows:

$$
\left[\begin{array}{c}
D d \\
D q
\end{array}\right]=2\left[\begin{array}{ccc}
\cos (\theta) & \cos \left(\theta-\frac{2 \pi}{3}\right) & \cos \left(\theta+\frac{2 \pi}{3}\right) \\
-\sin (\theta) & -\sin \left(\theta-\frac{2 \pi}{3}\right) & \sin \left(\theta-\frac{\pi}{3}\right)
\end{array}\right]\left[\begin{array}{c}
\operatorname{sign}\left(i_{a s}\right) \\
\operatorname{sign}\left(i_{b s}\right) \\
\operatorname{sign}\left(i_{c s}\right)
\end{array}\right]
$$

As seen from (15), it is evident that the distorted voltage due to VSI nonlinearity in the $d q$-axis reference frame is decomposed into $V_{c o m} D d$ and $V_{c o m} D q$. Assuming $\gamma$ is the angle between the current vector and $q$-axis, the simulated waveforms of $D d$ and $D q$ under $i_{d}=0$ control $(\gamma=0)$ are shown in Fig. 8 and Table III [30]. As can be seen from Table III, $D d$ and $D q$ are 6th order harmonics and will vary with $\theta_{e}=\theta+\pi / 2$. For example, the first mode, shown in Table III, $\operatorname{sign}\left(i_{a}\right)=1$, $\operatorname{sign}\left(i_{b}\right)=\operatorname{sign}\left(i_{c}\right)=-1, i_{d}=0$ and $\gamma=0$. There fore, $D d$ will vary from $-2\left(\theta_{e}=-\pi / 6\right)$ to $2\left(\theta_{e}=\pi / 6\right)$ while $D q$ will vary from 3.46 $\left(\theta_{e}=-\pi / 6\right)$ to $4\left(\theta_{e}=0\right)$. This is the reason why waveforms for $D d$ and $D q$ are so different in Fig. 8. Further, it is evident that the average value of distorted voltage in the $d$-axis reference frame is zero and the distorted voltage in the $q$-axis reference frame will introduce a DC voltage offset into the $q$-axis equation. This is the reason why the compensation of $V_{\text {com }} D d$ has no contribution to the estimation of $L_{q}$ and its influence on the estimation of $L_{q}$ can be neglected. In addition, as can be seen from the $d$-axis equation of (15), the term $U \cos (\phi)$ will influence the estimation of $L_{q}$. Thus, from Fig. 7(a), it is evident that the estimated $L_{q}(2.33 \mathrm{mH})$ will be far away from the nominal value $(3.24 \mathrm{mH})$ because $U$ is relatively large. However, from Fig. 7(b), it is evident that the estimated $L_{q}$ $(3.1 \mathrm{mH})$ will be much closer to the nominal value $(3.24 \mathrm{mH})$ because the measured $V_{m}$ is used for the real-time update of $V_{d c}$, which can minimize the term $U$ to a point at which it is negligible.

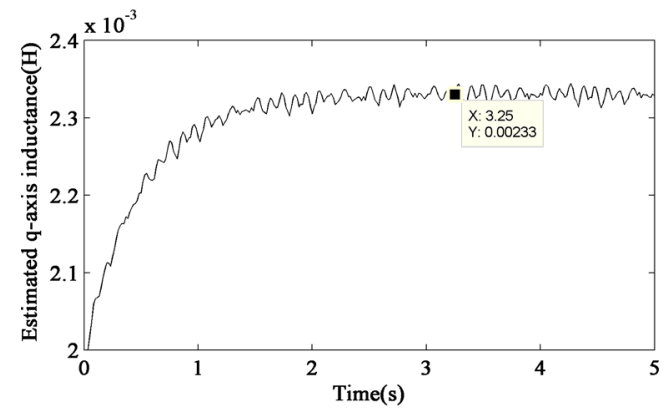

(a)

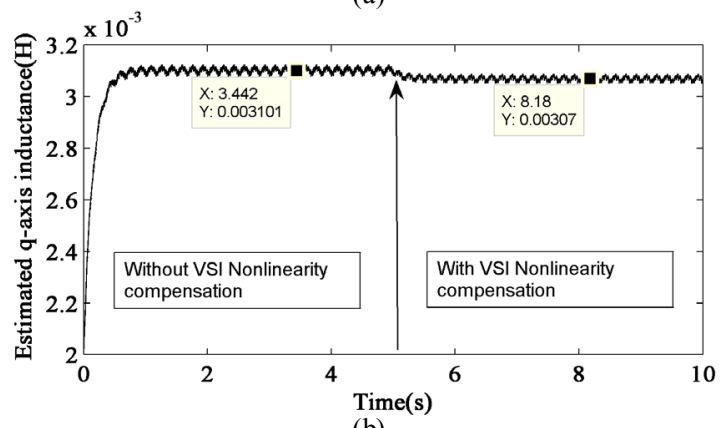

(b)

Fig. 7. Estimated $q$-axis inductance (under $i_{d}=0$ control). (a) Without taking into account the non-ideal voltage measurements. (b) With taking into account the VSI nonlinearity compensation, the measurement of DC bus voltage variation and the DC offset due to zero shift.

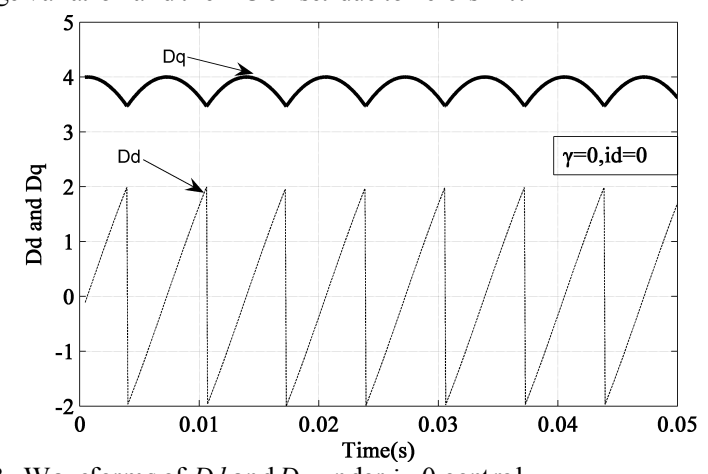

Fig. 8. Waveforms of $D d$ and $D q$ under $i_{d}=0$ control.

TABLE III

RELATIONSHIP BETWEEN CURRENT DIRECTIONS AND DQ-AXIS

\begin{tabular}{|c|c|c|c|c|c|}
\hline \multirow{2}{*}{$\theta_{e}=\theta+\pi / 2$} & \multicolumn{3}{|c|}{$\operatorname{sign}(i)$} & \multirow{2}{*}{$V_{\text {com }} D d$} & \multirow{2}{*}{$V_{\text {com }} D q$} \\
\hline & $i_{a}$ & $i_{b}$ & $i_{c}$ & & \\
\hline$-\pi / 6-\gamma \sim \pi / 6-\gamma$ & 1 & -1 & -1 & $4 V_{c o m} \sin \left(\theta_{e}\right)$ & $4 V_{\text {com }} \cos \left(\theta_{e}\right)$ \\
\hline$\pi / 6-\gamma \sim \pi / 2-\gamma$ & 1 & -1 & 1 & $4 V_{\text {com }} \sin \left(\theta_{e}-\pi / 3\right)$ & $4 V_{\text {com }} \cos \left(\theta_{e}-\pi / 3\right)$ \\
\hline$\pi / 2-\gamma \sim 5 \pi / 6-\gamma$ & -1 & -1 & 1 & $4 V_{c o m} \sin \left(\theta_{e}-2 \pi / 3\right)$ & $4 V_{\text {com }} \cos \left(\theta_{e}-2 \pi / 3\right)$ \\
\hline $5 \pi / 6-\gamma \sim 7 \pi / 6-\gamma$ & -1 & 1 & 1 & $4 V_{c o m} \sin \left(\theta_{e}-\pi\right)$ & $4 V_{\text {com }} \cos \left(\theta_{e}-\pi\right)$ \\
\hline $7 \pi / 6-\gamma \sim 3 \pi / 2-\gamma$ & -1 & 1 & -1 & $4 V_{c o m} \sin \left(\theta_{e}-4 \pi / 3\right)$ & $4 V_{\text {com }} \cos \left(\theta_{e}-4 \pi / 3\right)$ \\
\hline $3 \pi / 2-\gamma \sim 11 \pi / 6-\gamma$ & 1 & 1 & -1 & $4 V_{c o m} \sin \left(\theta_{e}-5 \pi / 3\right)$ & $4 V_{c o m} \cos \left(\theta_{e}-5 \pi / 3\right)$ \\
\hline
\end{tabular}
DISTORTED VOLT AGE

At $\omega=157 \mathrm{rad} / \mathrm{s}$, Fig. 9(a) shows the estimated stator winding resistance and rotor flux lin kage without taking into account the influence of non-ideal voltage measurement, which also shows that the estimated parameter values are far from their nominal values. Similarly, Fig. 9(b) shows the estimated stator winding resistance and rotor flux linkage, which have taken into account the measurement of the DC bus voltage variation and the DC offset due to zero shift. Compared with Fig. 9(a), Fig. 9(b) shows better estimation results compared with the parameter's nominal values shown in Table II. However, the estimated stator winding resistance value in Fig. 9(b) is still far from its nominal value because the distorted voltage due to VSI nonlinearity is not well compensated.

At $\omega=157 \mathrm{rad} / \mathrm{s}$, the corresponding $d q$-axis voltages and currents with or without VSI nonlinearity compensation are shown in Fig. 10. The VSI typical electrical parameters in 
Table I will be used to compute the distorted voltage $(E)$. In Fig. 10, there is no inverter nonlinearity compensation before $1.5 \mathrm{~s}$ and the compensation is added to the drive system after $1.5 \mathrm{~s}$. From Fig. 10, it is evident that the $d q$-axis voltages, obtained from the PI regulator, will slightly change following the addition of compensation. However, the $d q$-axis currents are maintained almost constant all the time since the load and specified $d$-axis current do not change.

The estimation results with or without compensation of VSI nonlinearity at $\omega=157 \mathrm{rad} / \mathrm{s}$ are compared in Fig. 9(c). It shows that the inverter nonlinearity compensation has significant influence on the winding resistance estimation but negligible influence on the rotor flux linkage estimation.

This can be analyzed as follows:

(a). By using typical electrical parameters in Table I and (14), the compensated voltage $E$ should be $-1.9 \mathrm{~V}$.

(b). The amplitude of compensated inverter nonlinearity voltage $(E=-1.9 \mathrm{~V})$ is significant (larger than 100\%) compared with $R i_{q} \approx 1.6 \mathrm{~V}$ and $R i_{d} \approx-0.7 \mathrm{~V}$. Further, $E$ is also significant compared with $R i_{q}+L \omega i_{d} \approx 0.6 \mathrm{~V}$ and $R i_{d}-$ $L \omega i_{q} \approx-2.9 \mathrm{~V}$. Therefore, after Clarke and Park transforms, the $d q$-axis voltage variation due to $E$ will influence the winding resistance estimation significantly.

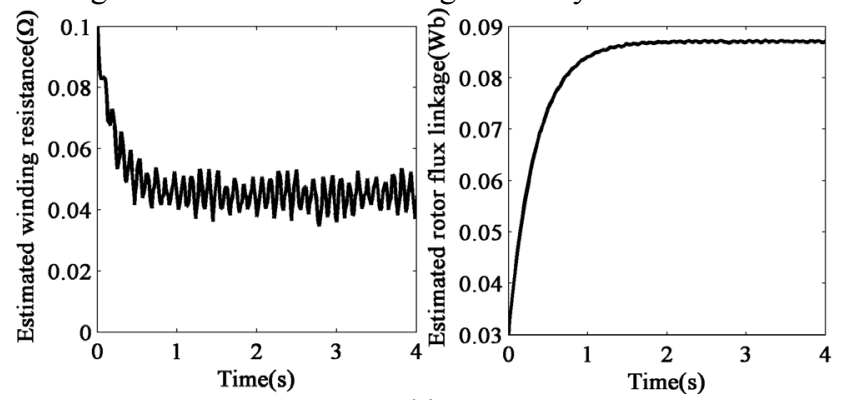

(a)
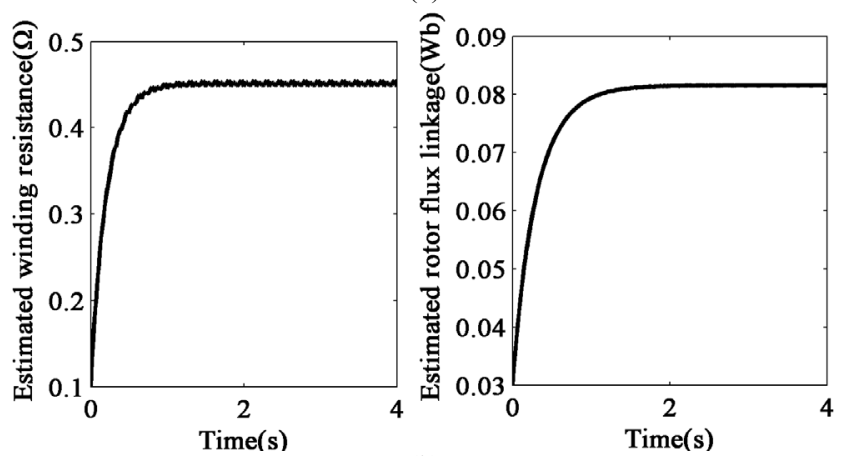

(b)
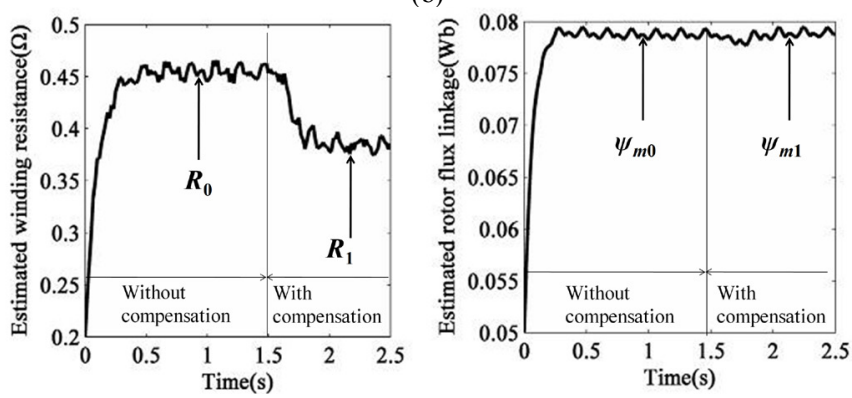

(c)

Fig. 9. Estimated stator winding resistance and rotor flux linkage $\left(i_{d}=2 \mathrm{~A}\right.$, $\omega=157 \mathrm{rad} / \mathrm{s}$ ). (a) Without taking into account the voltage measurement non-idealities. (b) With taking into account the measurement of DC bus voltage variation and the DC offset due to zero shift. (c) With taking into account the measurement of DC bus voltage variation, the DC offset due to zero shift and the VSI nonlinearity compensation. $\left(R_{0}=0.45 \Omega, R_{1}=0.39 \Omega\right.$, $\left.\psi_{m 0}=78.8 \mathrm{mWb}, \psi_{m l}=78.9 \mathrm{mWb}\right)$.

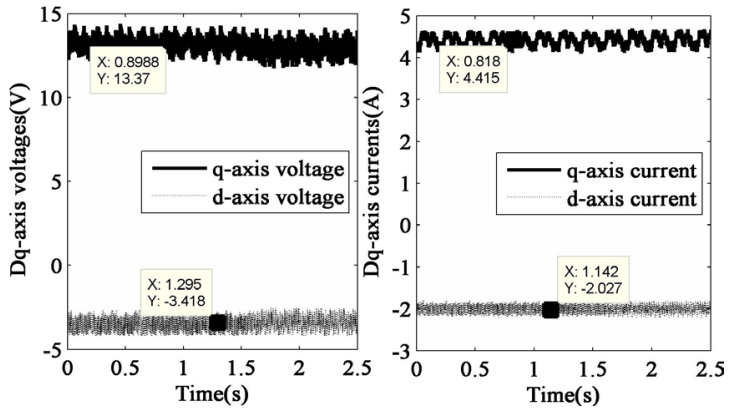

Fig. 10. Dq-axis currents and voltages with/without inverter compensation. COLLECTOR-EMITTER
SATURATION VOLTAGE CAARACTERISTICS FREE-WHEEL DIODE
FORWARD CHARACTERISTICS
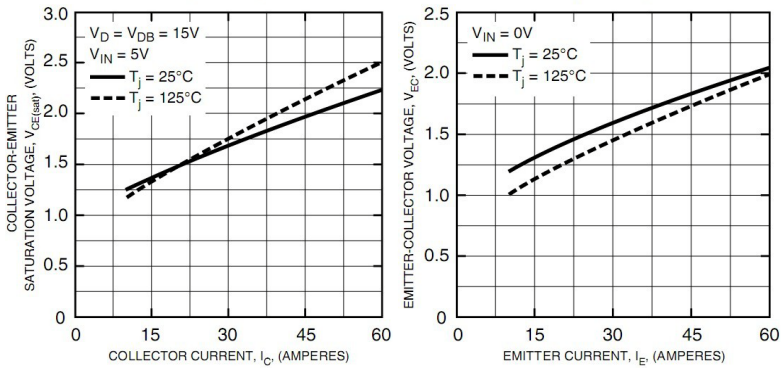

Fig. 11. Characteristics of the IGBT collector-emitter saturation voltage and the diode forward voltage.

(c). Since $\omega \psi_{m} \approx 12 \mathrm{~V}$ and $u_{q}=13.3 \mathrm{~V}$, the amplitude of $\omega \psi_{m}$ is as large as $12 / 13.3=90 \%$ compared with $u_{q}$ while $E$ is relatively small $(1.9 / 12=16 \%)$ compared with $\omega \psi_{m}$. After Clarke and Park transforms, shown in Fig. 10, the amplitude of the $q$-axis voltage variation due to $E$ is negligib le co mpared with $\omega \psi_{m}$ or $u_{q}$.

In addition, since the estimation is based on the $d q$-axis reference frame, the influence of $E$ on the estimation of $R$ and $\psi_{m}$ can be further analyzed by using the steady-state $d q$-axis equations for a PMSM at $i_{d}<0$. As can be seen from (15), in the $d q$-axis reference frame, $E$ can be decomposed into $D d V_{\text {com }}$ and $D q V_{\text {com }}$. Thus, the steady-state equations for a PMSM, including all the voltage measure ment non-idealities, can be shown as follows:

$$
\begin{array}{r}
u_{d}^{*}(k)+D d(k) V_{c o m}=R i_{d}(k)-L_{q} \omega(k) i_{q}(k)+U \cos (\phi) \\
u_{q}^{*}(k)+D q(k) V_{c o m}=R i_{q}(k)+L_{d} i_{d}(k) \omega(k)+\psi_{m} \omega(k) \\
-U \sin (\phi)(16 \mathrm{~b})
\end{array}
$$

Assuming accurate measurement of the DC bus voltage, (16) can be simplified to (17):

$$
\begin{aligned}
& u_{d}{ }^{*}(k)+D d(k) V_{\text {com }}=R i_{d}(k)-L_{q} \omega(k) i_{q}(k) \\
& u_{q}{ }^{*}(k)+D q(k) V_{c o m}=R i_{q}(k)+L_{d} \omega(k) i_{d}(k)+\psi_{m} \omega(k)
\end{aligned}
$$

Assuming the VSI nonlinearity is compensated properly, and the DC bus voltage is accurately measured, (17) can be simp lified to (18):

$u_{d}{ }^{*}(k)=R i_{d}(k)-L_{q} \omega(k) i_{q}(k)$

$u_{q}^{*}(k)=R i_{q}(k)+L_{d} \omega(k) i_{d}(k)+\psi_{m} \omega(k)$

As can be seen from (16)-(18), the estimation of $R$ mainly relies on the $d$-axis equation, and $R$ can be independently estimated from the $d$-axis equation if $i_{d}<0$. Furthermore, as can be seen from(16)-(18), the estimation of $\psi_{m}$ main ly relies on the $q$-axis equation and the parameter value of $R$ should be estimated prior to the estimation of $\psi_{m}$. Since the DC bus voltage is measured, the influence of $D d V_{\text {com }}$ and $D q V_{\text {com }}$ on the estimation of stator winding resistance and rotor flux linkage can be further analy zed as follows: 
Assuming that $R=R_{a}+\Delta R, R_{a}$ is the actual stator winding resistance and $\Delta R$ is the estimation error due to VSI nonlinearity. Since the DC bus is accurately measured, $\Delta R$ can be derived from (17a) and shown as:

$$
\Delta R=\frac{D d(k) V_{c o m}}{i_{d}(k)}
$$

If the estimation is with compensation, the DC components of $D d V_{\text {com }}$ and $D q V_{\text {com }}$ will be minimized to negligib le values and (17) will be simplified to (18). Based on (18a), the estimated $R$ will be close to $R_{a}$ because its accuracy mainly relies on the $d$-axis equation. Therefore, by using the estimated $R$ from (18a), $\psi_{m}$ can be estimated from (18b) then and the estimated $\psi_{m}$ will be close to its actual value because $R$ is close to $R_{a}$ and $D q V_{\text {com }}$ becomes negligible.

If the compensation of VSI nonlinearity is not taken into account, it is evident from (19) that the estimated $R=R_{a}+\Delta R$ will be significantly larger than $R_{a}$, which is experimentally shown in Fig. 9(b). Furthermo re, since $\Delta R$ is not equal to zero, the term $D q V_{\text {com }}$ in (17b) will be partly counteracted by $\Delta R i_{q}$ because the estimated $R=R_{a}+\Delta R$ is used to assist the estimation of $\psi_{m}$, which is a reason why the variation of estimated $\psi_{m}$ with or without the compensation is quite small. Assuming that $\Delta \psi_{m}$ is the estimation error due to $D q V_{\text {com }}$ and $\Delta R, \Delta \psi_{m}$, it can be derived from (17b) and shown as follows:

$$
\begin{aligned}
\Delta \psi_{m} & =\frac{D q(k) V_{c o m}-\Delta R i_{q}(k)}{\omega(k)} \\
& =\left|\frac{D d(k) V_{c o m} i_{q}(k)}{i_{d}(k) \omega(k)}\right|-\left|\frac{D q(k) V_{c o m}}{\omega(k)}\right|
\end{aligned}
$$

From Table III, the DC components of $D d(k)$ and $D q(k)$ are close to $4 \sin (\gamma)$ and $4 \cos (\gamma)$, respectively. In addition, $\cot (\gamma)=i_{q}(k) / i_{d}(k)$. Therefore, assuming that $\Delta \bar{\psi}_{m}$ is the DC component of (20), it can be expressed as:

$$
\Delta \bar{\psi}_{m} \approx \frac{|\sin (\gamma) \cot (\gamma)|-|\cos (\gamma)|}{\omega(k)}\left|4 V_{c o m}\right|=0
$$
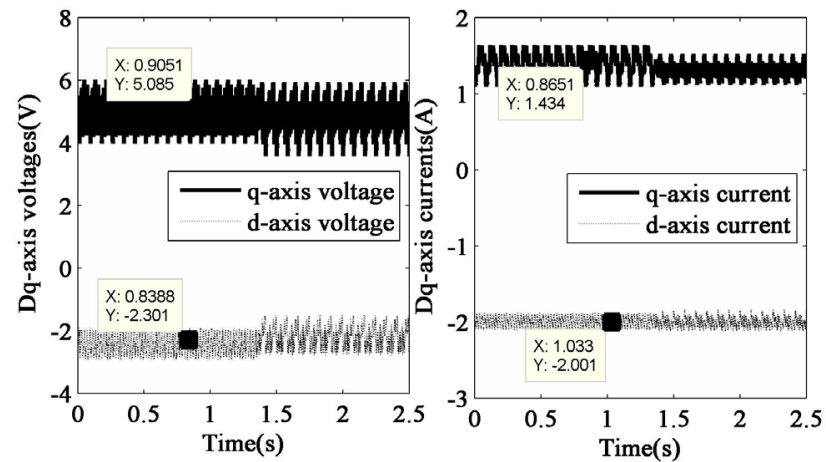

Fig. 12. Dq-axis currents and voltages with/without compensation.
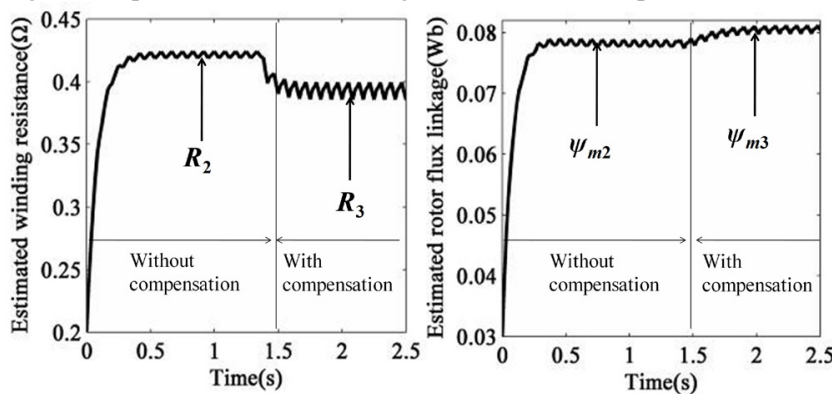

Fig. 13. Winding resistance and rotor flux linkage estimation results with taking into account the measurement of DC bus voltage variation, the DC offset due to zero shift and the VSI nonlinearity compensation. $(\omega=52.3 \mathrm{rad} / \mathrm{s}$, $R_{2}=0.42 \Omega, R_{3}=0.39 \Omega, \psi_{m 2}=78.6 \mathrm{mWb}, \psi_{m 3}=80.0 \mathrm{mWb}$ ).
(21) is the expression for the rotor flux linkage estimation error, due to VSI nonlinearity, which shows that there is cancellation in the numerator and the DC component of $\Delta \psi_{m}$ is close to 0 . Therefore, this is the reas on why the variation of $\psi_{m}$ with or without the compensation is negligible compared with $\psi_{m}$. Thus, although the computed inverter nonlinearity voltage $E$ is as large as -1.9 , it has negligible influence on the estimation of $\psi_{m}$, but significant influence on the estimation of $R$. Fig. 11 shows the characteristics of the IGBT collector-emitter saturation voltage and the diode's forward voltage, which is cited from the datasheet of Mitsubishi ps $21867-$ p. At $\omega=52.3 \mathrm{rad} / \mathrm{s}$, the corresponding $d q$-axis voltages and currents with or without compensation are shown in Fig. 12. From Fig. 11 and Fig. 12, the computed $E$ will be $-1.3 \mathrm{~V}$ at $\omega=52.3 \mathrm{rad} / \mathrm{s}$. In Fig. 13, there is no inverter compensation before $1.5 \mathrm{~s}$ and the compensation added to the drive system after $1.5 \mathrm{~s}$. At $\omega=52.3 \mathrm{rad} / \mathrm{s}, \omega \psi_{m} \approx 4 \mathrm{~V}$ and it is obvious that $E=-1.3 \mathrm{~V}$ is not negligible compared with $\omega \psi_{m}$. Further, since $\Delta \psi_{m}$ can not be exactly equal to 0 and the voltage drop of $\omega \psi_{m}$ at $52.3 \mathrm{rad} / \mathrm{s}$ is much smaller than the voltage drop at $157 \mathrm{rad} / \mathrm{s}$, the variation of estimated $\psi_{m}$ with or without the compensation of VSI nonlinearity will be significant. Therefore, the estimated rotor flux linkage and stator winding resistance in Fig. 13 is different from Fig. 9(c), and both vary significantly.

In addition, for most PMSM, the voltage drop due to the stator winding resistance $\left(R i_{q}\right)$ is usually quite small compared with the back EMF voltage $\left(\omega \psi_{m}\right)$ when operating at rated speed. This is because a large stator winding resistance will increase the heat losses due to the stator current and will cause the power efficiency to decrease. Although some special PMSM, for high speed applications, have small $\psi_{m}$ its back EMF voltage at rated speed is still much larger than $R i_{q}$. Thus, in this paper, the conclusion based on the example PMSM in Table II is suitable for most PMSM in real applications. Furthermore, for those special PMSM, the PMSM with a large stator winding resistance and small back EMF voltage $\left(\omega \psi_{m}\right)$, the VSI nonlinearity compensation will have significant influence on both the rotor flux linkage and winding resistance estimation irrespective of low or high speed operation.

\section{CONCLUSION}

This paper systematically investigates the influence of non-ideal voltage measurements on the parameter estimation for PMSM. From the experimental results and theoretical analysis, it is evident that the VSI nonlinearity compensation has negligible influence on the estimation of rotor flux linkage, but significant influence on the estimation of winding resistance at high speeds. However, at low speeds, the VSI nonlinearity compensation has significant influence on both the rotor flux linkage and winding resistance estimation. Further, the estimation accuracy of PMSM parameters depends on their $d q$-axis voltage drop compared with the distorted inverter voltage, if the VSI nonlinearity compensation is not employed. In addition, under $i_{d}=0$ control, the estimation of the $q$-axis inductance will not be influenced by the VSI nonlinearity compensation but will be significantly influenced by the non-ideal measurement of varying the DC bus voltage and zero shift in the amplifier. In addition, the analysis and conclusion based on the used 
MRAS estimator can be applied to other estimators based on solving the steady-state PMSM equations using the measured stator currents and voltages.

\section{APPENDIX A}

From (3) and (4), assuming that $e=X-\hat{X}=\left[\begin{array}{l}e_{1} \\ e_{2}\end{array}\right]$, an error state equation can be obtained as follows:

$\dot{e}=A X-\hat{A} \hat{X}+B r-B \hat{r}+C l-\hat{C} \hat{l}$

$=A X-A \hat{X}+A \hat{X}-\hat{A} \hat{X}+B r-\hat{B} r+C l-\hat{C} l$

$=A e+(A-\hat{A}) \hat{X}+(B-\hat{B}) r+(C-\hat{C}) l$

Let $\hat{\alpha}-\alpha=a, \quad A-\hat{A}=(\hat{\alpha}-\alpha) I=a I, \quad b=B-\hat{B}=$ $\left(\frac{1}{L}-\frac{1}{\hat{L}}\right), \quad C-\hat{C}=\frac{\hat{\psi}_{m}}{\hat{L}}-\frac{\psi_{m}}{L}=g, \phi^{T}=[a, b, g], \quad s=$ $\left[\begin{array}{lll}\hat{X} & r & l\end{array}\right]^{T}$.

Then, equation (A1) can be transferred into (A 2): $\dot{e}=A e+\phi^{T} s$

Design a Lyapunov function below, which is positive definite.

$V(X, t)=\frac{1}{2}\left(e^{T} P e+\phi^{T} \Gamma \phi\right)$

where $P=\left[\begin{array}{ll}1 & 0 \\ 0 & 1\end{array}\right]=P^{T}, \Gamma=\Gamma^{T}=\left[\begin{array}{lll}1 & 0 & 0 \\ 0 & 1 & 0 \\ 0 & 0 & 1\end{array}\right]$ and $V(X, t)$ is positive definite. Lyapunov second theorem on stability is emp loyed here to ensure the global asymptotic stability of the system and $e=\phi^{T}=0$ is set as the stable equilibrium point. The theorem is quoted as follows:

1: $V(X, t)$ is positive definite.

2: $\dot{V}(X, t)$ is negative definite.

3: $V(X, t)$ is infinite when $|X| \rightarrow \infty$.

It is obvious that conditions (1) and (3) are achieved and the condition (2) is discussed as follows:

$$
\begin{aligned}
& \dot{V}(X, t)=\frac{1}{2}\left(\dot{e}^{T} P e+e^{T} P \dot{e}+\dot{\phi}^{T} \Gamma \phi+\phi^{T} \Gamma \dot{\phi}\right) \\
& \dot{e}^{T} P e+e^{T} P \dot{e}=e^{T}\left(P A+A^{T} P\right) e+s^{T} \phi P e+e^{T} P\left(\phi^{T} s\right) \\
& \dot{\phi}^{T} \Gamma \phi+\phi^{T} \Gamma \dot{\phi}=2(a \dot{a}+b \dot{b}+g \dot{g}) \\
& \Rightarrow \dot{V}(X, t)=\frac{1}{2} e^{T}\left(P A+A^{T} P\right) e+\frac{1}{2}\left(s^{T} \phi P e+e^{T} P\left(\phi^{T} s\right)\right)+a \dot{a} \\
& +b \dot{b}+g \dot{g}, P A+A^{T} P=\left[\begin{array}{rr}
-2 \alpha & \\
-2 \alpha
\end{array}\right]
\end{aligned}
$$

where $\alpha=\frac{R}{L}>0$, it is obvious that $\frac{1}{2} e^{T}\left(P A+A^{T} P\right) e$ is negative definite.

$$
\begin{aligned}
& \frac{1}{2}\left(s^{T} \phi P e+e^{T} P\left(\phi^{T} s\right)\right) \\
& =a \hat{i_{d}}\left(i_{d}-\hat{i}_{d}\right)+a \hat{i_{q}}\left(i_{q}-\hat{i}_{q}\right)+b u_{d}\left(i_{d}-\hat{i}_{d}\right)+\left(b u_{q}+\omega g\right)\left(i_{q}\right. \\
& \left.-\hat{i}_{q}\right)
\end{aligned}
$$

Therefore,
$\dot{V}(X, t)=\frac{1}{2} e^{T}\left(P A+A^{T} P\right) e+a \hat{i_{d}}\left(i_{d}-\hat{i_{d}}\right)+a \hat{i_{q}}\left(i_{q}-\hat{i}_{q}\right)+$

$b u_{d}\left(i_{d}-\hat{i}_{d}\right)+\left(b u_{q}+\omega g\right)\left(i_{q}-\hat{i}_{q}\right)+a \dot{a}+b \dot{b}+g \dot{g}$

$=a\left(\hat{i_{d}}\left(i_{d}-\hat{i_{d}}\right)+\hat{i}_{q}\left(i_{q}-\hat{i_{q}}\right)+\dot{a}\right)+b\left(u_{d}\left(i_{d}-\hat{i_{d}}\right)+u_{q}\left(i_{q}-\hat{i_{q}}\right)+\right.$

b) $+g\left[\omega\left(i_{q}-\hat{i}_{q}\right)+\dot{g}\right]+\frac{1}{2} e^{T}\left(P A+A^{T} P\right) e$

Then, the MRAS based stator inductance, winding resistance and rotor flux linkage estimators can be designed by following steps:

Let

$b\left(u d\left(i_{d}-\hat{i}_{d}\right)+u_{q}\left(i_{q}-\hat{i}_{q}\right)+\dot{b}\right)=0$

$a\left(\hat{i}_{d}\left(i_{d}-\hat{i}_{d}\right)+\hat{i}_{q}\left(i_{q}-\hat{i}_{q}\right)+\dot{a}\right)=0$

$\dot{g}+\omega\left(i_{q}-\hat{i}_{q}\right)=0$

It is obvious that $\dot{V}(X, t)$ is negative definite and condition (2) is satisfied. Hence, the SPMSM stator inductance, winding resistance and rotor flux linkage can be obtained from (A5), (A6) and (A7), respectively:

$\frac{1}{\hat{L}}=\frac{1}{L_{0}}+\int_{0}^{t}\left[u_{d}\left(i_{d}-\hat{i}_{d}\right)+u_{q}\left(i_{q}-\hat{i}_{q}\right)\right] d t$

$\hat{R}=R_{0}-\hat{L} \int_{0}^{t}\left[\hat{i}_{d}\left(i_{d}-\hat{i}_{d}\right)+\hat{i}_{q}\left(i_{q}-\hat{i}_{q}\right)\right] d t$

$\hat{\psi}_{m}=\psi_{m 0}-\hat{L} \int_{0}^{t} \omega\left(i_{q}-\hat{i}_{q}\right) d t$

where $L_{0}, R_{0}$ and $\psi_{m 0}$ are the initial values of estimated inductance, winding resistance and rotor flux linkage.

\section{REFERENCES}

[1] T. Orlowska-Kowalska, and M. Dybkowski, "Stator-current-based MRAS estimator for a wide range speed-sensorless induction-motor drive," IEEE Trans. Ind. Electron., vol. 57, no. 4, pp. 1296-1308, Apr. 2010 .

[2] M.S. Zaky, M.M. Khater, S.S. Shokralla, and H.A. Yasin, "Parameter identification scheme of sensorless indution mot or drives," IEEE Trans Ind. Electron., vol. 56, no. 5, pp. 1699-1707, May 2009.

[3] S. Rao, M. Buss, and V. Utkin, "Simultaneous state and parameter estimation in induction motors using first- and second-order sliding modes," IEEE Trans. Ind. Electron., vol. 56, no.9, pp. 3369-3376, Sep. 2009.

[4] B. N. Mobarakeh, F. Meibody-Tabar, and F.M. Sargos, "Mechanical sensorless control of PMSM with online estimation of stator resistance," IEEE Trans. Ind. Applicat., vol. 40, no. 2, pp. 457-471, Mar./Apr. 2004.

[5] M. Rashed, P.F.A. Macconnell, A.F. Stronach, and P. Acarnley, "Sensorless indirect-rotor-field-orientation speed control of a permanent-magnet synchronous motor with stator-resistance estimation," IEEE Trans. Ind. Electron., vol. 54, no. 3, pp. 1664-1675, Jun. 2007.

[6] L. Liu, and D.A. Cartes, "Synchronisation based adaptive parameter identification for permanent magnet synchronous motors," IET Control Theory Appl., , vol. 1, no. 4, pp. 1015-1022, Jul. 2007.

[7] T. Senjyu, K. Kinjo, N. Urasaki, and K. Uezato, "Parameter measurement for PMSM using adaptive identification," in Proc. IEEE Intemational Symposium on Ind. Electron., 2002, vol. 3, pp. 711-716.

[8] S. Bolognani, M. Zigliotto, and K. Unterkofler. "On-line parameter commissioning in sensorless PMSM drives," in Proc. IEEE Intemational Symposium on Ind. Electron., 1997, vol. 2, pp. 480-484.

[9] S. Ichikawa, M. Tomita, S. Doki, and S. Okuma, "Sensorless control of permanent-magnet synchronous motors using online parameter identification based on system identification theory," IEEE Trans. Ind. Electron., vol. 53, no. 2, pp. 363-372, Apr. 2006.

[10] S. Underwood, and I. Husain, "On-line parameter estimation and adaptive control of permanent magnet synchronous machines," IEEE Trans. Ind. Electron., vol. 57, no. 7, pp. 2435-2443, Jun. 2010. 
[11] Z. Gao, R.S. Colby, L. Turner, and B. Leprettre, "Filter desgin for estimating parameters of induction motors with time-varying loads," IEEE Trans. Ind. Electron., vol. 58, no. 5, pp. 1518-1529, May 2011.

[12] K. Liu, Q. Zhang, J.T. Chen, Z.Q. Zhu, J. Zhang, and A.W. Shen, "Online multi-parameter estimation of non-salient pole PM synchronous machines with temperature variation tracking," IEEE Trans. Ind. Electron., vol. 58, no. 5, pp. 1776-1788, May 2011.

[13] Z.Q. Zhu, X. Zhu, and P.D. Sun, "Estimation of winding resistance and PM flux-linkage in brushless AC machines by reduced-order extended Kalman Filter," in Proc. IEEE Intemational Conference on Networking Sensing and Control, 2007, pp. 740-745.

[14] K.W. Lee, D.H. Jung, and I.J. Ha, "An online ident ificat ion method for both stator resistance and back-EMF coefficient of PMSMs without rotational transducers," IEEE Trans. Ind. Electron., vol. 51, no. 2, pp 507-510, Apr. 2004.

[15] M.A. Jabbar, J. Dong, and Z. Liu, "Determination of machine parameters for internal permanent magnet synchronous motors," in Proc. Power Electron., Mach. and Drives, 2004, vol. 2, pp. 805-810.

[16] U. Schaible, and B. Szabados, "Dynamic motor parameter identification for high speed flux weakening operation of brushless permanent magnet synchronous machines," IEEE Trans. Energy Convers., vol. 14, no. 3, pp. 486-492, Sep. 1999.

[17] .D. Reigosa, F. Briz, P. Gacia, J.M. Guerrero, and M.W. Degner, "Magnet temperature estimation in surface PM machines using high-frequency signal injection," IEEE Trans. Ind. Applicat., vol. 46, no. 4, pp. 1468-1475, Jul./Aug. 2010.

[18] A. Piippo, M. Hinkkanen, and J. Luomi, "Adaptation of motor parameters in sensorless PMSM drives," IEEE Trans. Ind. Applicat, vol. 45, no. 1, pp. 203-212, Jan./Feb. 2009.

[19] A. Bechouche, H. Sediki, D.O. Abdeslam, and S. Haddad, "Identification of induction motor at standstill using artificial neural net work," in Proc. 36th Annual Conf. of the IEEE Ind. Electron. Society, 2010, pp. 2908-2913.

[20] M.K. Mishra, and K. Karthikeyan, "An invesitigation on design and switching dynamics of a voltage source inverter to compensate unbalanced and nonlinear loads," IEEE Trans. Ind. Electron., vol. 56, no. 8, pp. 2802-2810, Aug. 2009.

[21] R. Raute, C. Caruana, and C.S. Staines, "Analysis and compensation of inverter nonlinearity effect on a sensorless PMSM drive at very low and zero speed operation," IEEE Trans. Ind. Electron., vol. 57, no. 12, pp. 4065-4074, Dec. 2010.

[22] M.F. Iacchetti, "On line tuning of the stator inductance in a MRAS observer for sensorless DFIM drives," in Proc. 19th ICEM, 2010, pp. $1-6$.

[23] Y.C. Shi, K. Sun, H.Y. Ma, and L.P. Huang, "Permanent magnet flux identification of IPMSM based on EKF with speed sensorless control," in Proc. 36th Annual Conf. of the IEEE Ind. Electron. Society, 2010,pp. 2252-2257.

[24] S. Morimoto, M. Sanada, and Y. Yakeda, "Mechanical sensorless drives of IPMSM with online parameter ident ification," IEEE Trans. Ind. Applicat., vol. 42, no. 5, pp. 1241-1248, Sept./Oct, 2006.

[25] J.W. Choi, and S. K. Sul, "A new compensation strategy reducing voltage/current distortion in PWM VSI systems operating with low output voltages," IEEE Trans. Ind. Applicat, vol. 31, no. 5, pp. 1001-1008, Sep. 1995.

[26] J.W. Choi and S.K. Sul, "Inverter output voltage synthesis using novel dead time compensation," IEEE Trans. Power Elctron., vol. 11, no. 2, pp. 221-227, Mar. 1996.

[27] R. Munoz and Thomas A. Lipo, "On-line dead-time compensation technique for open-loop PWM-VSI drives," IEEE Trans. Power Electronics, vol. 14, no. 4, pp. 683-689, Jul. 1999.

[28] H. S. Kim, K. H. Kim, and M. J.Youn, "On-line dead-time compensation method based on time delay control," IEEE Trans. Contr. Syst. Technol., vol. 11, no. 2, pp. 279-285, Mar./Apr., 2003.

[29] H.W. Kim, H. S. Kim, M. J. Youn, and K.W. Cho, "On-line observation and compensation of voltage dist ortion in PWM VSI for PMSM,"Proc. Inst. Elect. Eng. - B, Electron. Power Appl., vol. 151, no. 5, pp. 534-542, Sep. 2004.

[30] H.W. Kim, M.J. Youn, K.Y. Cho, and H.S. Kim, "Nonlinearity est imation and compensation of PWM VSI for PMSM under resistance and flux linkage uncertainty," IEEE Trans. Contr. Syst. Technol., vol. 14, no. 4, pp. 589-601, Jul. 2006.

[31] H.W. Kim, M.J. Youn, and K.Y. Cho, "New voltage distortion observer of PWM VSI for PMSM," IEEE Trans. Ind. Electron., vol. 52, no. 4, pp. 1188-1 192, Aug. 2005.

[32] S.Y. Kim, W. Lee, M.S. Rho, and S.Y. Park, "Effective dead-time compensation using a simple vectorial disturbance estimator in PMSM drives," IEEE Trans. Ind. Electron., vol. 57, no. 5, pp. 1609-1614, May 2010.

[33] Y. Nakamura, H. Funato, and S. Ogasawara, "Compensation of output voltage distortion analysis of PWM inverter with LC filter caused by device voltage drop," in Proc. 2007 European Conf. on Power Electron. and Applicat., Sep. 2007, pp. 1-9.

[34] H.S. Ryu, I.H. Lim, J.H. Lee, S.H. Hwang, and J.M. Kim, “A dead time compensation method in voltage-fed PWM inverter," in Proc. IEEE 41st Ind. Applicat. Society Annual Meeting, Oct. 2006, vol. 2, pp. 911-916.

[35] S.H. Hwang, and J.M. Kim, "Dead time compensation method for voltage-fed PWM inverter," IEEE Tran. Energy Convers., vol. 25, no. 1, pp. 1-9, Mar. 2010.

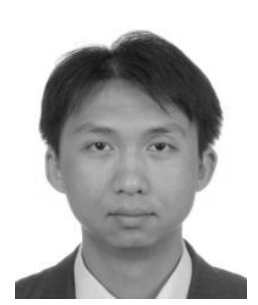

Kan Liu received the B.Eng. degree in automation from the Hunan University, China, in 2005, where he then started his courses for a joint Master/PHD degree. In 2008, he was supported by the China Scholarship Council to go on his study as a joint $\mathrm{PhD}$ student/Visiting Student at the University of Sheffield, Sheffield, U.K. He is currently working in the Department of Electronics and Electrical Engineering at the University of Sheffield. His research interest focuses on brushless ACmotor parameters estimation by controltheory and nonlinearity compensation for VSI output voltage.

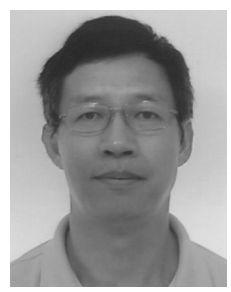

Z. Q. Zhu (M'90-SM'00-F'09) received the B.Eng. and M.Sc. degrees in electrical and electronic engineering from Zhejiang University, Hangzhou, China, in 1982 and 1984, respectively, and the Ph.D. degree in electrical and electronic engineering from the University of Sheffield, Sheffield, U.K., in 1991. From 1984 to 1988, he was a Lecturer with the Department of Electrical Engineering, Zhejiang University. Since 1988, he has been with the University of Sheffield, where he was initially a Research Associate and was subsequently appointed to an established post as Senior Research Officer/Senior Research Scientist. Since 2000, he has been a Professor of Electrical Machines and Control Systems with the Department of Electronic and Electrical Engineering, University of Sheffield, and is currently Head of the Electrical Machines and Drives Research Group and Director of Sheffield Siemens Wind Power Research Centre. His current major research interests include design and control of permanent magnet brushless machines and drives, for applications ranging from automotive, aerospace, to renewable energy. He is a Fellow of IEEE.

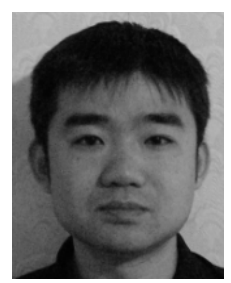

Qiao Zhang received his B.Eng. and M.SC. degrees in the Department of Control Science and Technology from Huazhong University of Science andTechnology, Wuhan, China, in 2003 and 2006. In 2008, he was supported by China Scholarship Council to go on his study as a joint PHD student/visiting student at the University of Sheffield, U.K. He is currently with the Department of Control Science and Engineering, Huazhong University of Science and Technology. His research interest focuses on brushless $\mathrm{AC}$ motor parameters estimation and machine drives design.

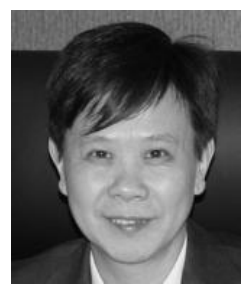

Jing Zhang received his B.Eng., M.Sc. and PHD degrees from Hunan University, China, in 1982 , 1984 and 1997, respectively. He is currently with the School of Electrical and Information Engineering, Hunan University. He has published more than 100 papers in journals and conferences. His research interests are in optimal, fuzzy and intelligent control of rotary kilns. Prof. Zhang was the recipient of the China National Second Prize of Scientific and T echnological progress. 